\title{
Predicting Participation in Volunteering Based on Personality Characteristics
}

\author{
Hanif Akhtar \\ Faculty of Psychology, University of Muhammadiyah Malang \\ Malang, Indonesia \\ hanifakhtar@umm.ac.id
}

\begin{abstract}
The main goal of this research was to examine whether big five personality traits can predict participation in volunteering. A total of 420 participants consisting of 215 volunteers and 205 nonvolunteers from various regions in Indonesia completed an inventory of the big five personality traits. The preliminary analysis using independent sample t-test found that the openness, extraversion, agreeableness, conscientiousness, and emotional stability of volunteer samples were significantly higher than non-volunteer samples. Binary logistic regression analysis then was used to examine whether each of the big five personality traits was able to predict the participation to be a volunteer. The logistic regression model was statistically significant with $\chi 2=67,102, p<, 01$. The model explained 19,7\% (Nagelkerke $R^{2}$ ) of the variance in volunteer participation and correctly classified $64 \%$ of cases. Increasing extraversion and conscientiousness was significantly associated with an increased likelihood of volunteer participation. Thus, certain personality characteristics can predict participation in volunteering
\end{abstract}

Keywords: Big five personality traits, logistic regression, volunteer

\section{Introduction}

In Indonesian society context, volunteerism has been practiced in daily life, such as "gotongroyong" (mutual cooperation) in the development of public facilities, marriage, and death (Savitri, 2005). Volunteerism covers a variety of different behaviors purposed at helping individuals and society. Although these actions are commonly intended to make a better society, the background and motivation of volunteers to help is different. Volunteering are generally defined as any planned and non-obligated activities in which time and effort are given with no expected payment to provide positive impact another individual or organization (Snyder \& Omoto, 2008; Wilson, 2000). 
Almost all of the non-profit organizations must rely on volunteers to achieve their mission (Clary, Snyder, \& Ridge, 1992). Empirical findings show that organizations can enhance their performance and get a lot of benefits if they can maintain the existence of volunteers (Skoglund, 2006). They need support from volunteers to get involved in their programs or supporting their operational costs. Without volunteers who donate their time, energy, and materials, the non-profit organizations would not be able to serve as effectively as they do. As a result, there is a lot of interest in the factors that make people choose to be a volunteer.

In addition to having a positive impact on non-profit organizations, volunteerism also has a positive impact on the volunteers themselves. Windsor, Anstey, \& Rodgers (2008), identified that volunteer gets some benefits, such as physical health as well as better mental health. Gastañaduy, Paredes, \& Lens (2014) identified that the non-volunteer group has lower intrinsic motivation scores than volunteer group. Also, intrinsic motivation correlates positively significantly with well-being. Akhtar (2017) mentioned advantages perceived as volunteers such as developing personal competence, increasing insight and knowledge, gaining inner satisfaction, expanding social relations and becoming more grateful. Recently, researchers found that Being a volunteer had a positive effect on individual mental health and well-being (Whillans et al., 20I7; Tabassum, Mohan, Smith, 2016).

Some research aims to find out what factors influence people to become a volunteer. Clary et al. (1998) argued that traits and dispositions are the key motivators to volunteer rather than situational factors. Omoto and Snyder (1995) agreed and suggested that people tend to be a volunteer because of their personality characteristics, needs, and motivations. Other researchers also have determined that personality traits, as a relatively steady trait in adulthood, have an impact on participation in voluntary activities (Pushkar, Reis, \& Morros, 2002). Empirical researchers found that having a specific personality characteristics can predict participation in volunteering and being more effective as volunteers (Gu et al., 2013; Omoto, Snyder and Hackett, 20I0; Carlo, Okun, Knight, \& De Guzman, 2005; Herzog \& Morgan, 1993; Spitz \& MacKinnon, 1993). 
Researchers had investigated the personality characteristics that differentiate between individuals who decide to volunteer or not. Herzog and Morgan (1993) found that the most crucial personality characteristics that predict volunteering are higher levels of extraversion and lower levels of neuroticism. Agreeableness is the core characteristics contributing to prosocial behaviors, that is manifested on volunteering (Graziano \& Eisenberg, 1997). Omoto, Snyder, and Hackett (2010) found that AIDS activism was significantly correlated with emotional stability, extraversion, and agreeableness. Recently, Gu et al. (20I3) compared the personality characteristics between volunteer and non-volunteer at Shanghai Expo. Based on the data of I6PF, they found that warmth, liveliness, boldness, and extroversion scores of volunteer are significantly higher than non-volunteer samples. McCann (2017) found that neuroticism negatively correlated highly with state volunteering rates.

Previous studies mostly discriminate between individuals who decide to volunteer or not based on Cattell's 16 Personality Factors. However, today, the most widely acknowledged and applied model representing individual personality traits is the big five personality model (McCrae, 2009). Only a few studies were conducted based on the big five personality model. The survey of Juzbasic \& Vukasovic Hlupic (2015) is one of the studies that examined the motivation to volunteers based on the big five personality traits on. Unfortunately, motivation itself is not always manifested in the behavior of volunteering. This study will focus on distinguishing between people who decide to volunteer or not based on big five personality traits. Moreover, this study also wanted to find out what kind of specific personality characteristics were dominant to increase the tendency to become volunteers by using binary logistic regression analysis.

Although there are a large number of volunteers in Indonesia, and there are a lot of advantages to volunteering, studies that examine the characteristics of volunteers in Indonesia are still rare. I have traced the Google Scholar database related to the articles with the keywords"karakteristik relawan" and "kepribadian relawan" for the past five years. As a result, as of April 2019, there were only less than ten articles containing the keywords "karakteristik relawan" and "kepribadian relawan."This information is needed by the organization to frame their recruitment messages to attract applicants with certain 
personality characteristics. Moreover, this information can be useful to assess potential differences in a specific volunteer population to differentiating the variables that might predict success or failure in volunteer community services (Spitz \& MacKinnon, 1993).

Overall, the main goal of this research was to explore whether big five personality traits can predict participation in volunteering. This study also attempts to examine volunteers' personality characteristics, in hope to provide the reference for relevant organizations to recruit and manage their volunteers. That information can be useful for organizations to handle individual differences and personality tests for new prospective employees. The following research questions: Is there any different personality characteristics between volunteer and non-volunteer? What kind of specific personality characteristics was dominant to increase the tendency to become volunteers?

\section{Method}

Participants

Participants are Indonesian citizens aged teenagers and adults. The sampling technique used in this study was purposive sampling. The criteria set out for the volunteer sample in this study were individuals who have ever involved as volunteers in various fields. The total of the participants were 420 people divided into two groups, that is volunteer groups and nonvolunteer groups. Volunteer participants were 215 people, while non-volunteer participants were 205 people. Participants filled out the online survey were came from various regions in Indonesia. The percentage of female participants were $66,4 \%(\mathrm{~N}=279)$ and the percentage of male participants were $33,6 \%(\mathrm{~N}=|4|)$. The age of all the participants ranged between 18 to 55 years old with Mean of 25,11 and SD of 5,85 .

\section{Measurement}

Ten Item Personality Inventory (TIPI)

TIPI is a standard and brief open-source instrument measuring the big five personality traits (Agreeableness, Conscientiousness, Extraversion, Emotional Stability, and Openness). TIPI comprises of ten items, each of them being a combination of descriptive words. There was a 7-point scale ranging from I (strongly disagree) to 7 (strongly agree), and the participant 
should respond to all of the items(Gosling, Rentfrow, \& Swann, 2003). TIPI has been translated and validated into Indonesian by Akhtar (2018). The example items of TIPI were “kalem, pendiam"(extraversion), “cemas, mudah marah" (emotional stability), and "tidak sistematis, kurang berhati-hati" (conscientiousness). The TIPI Indonesia has satisfactory discriminant and convergent validity related to the Big Five Inventory (BFI) and satisfactory levels of test-retest reliability. The test-retest reliability coefficient for each of the big five personality dimensions is as follows: Emotional Stability $(\alpha=0,74)$, Extraversion $(\alpha=0,85)$, Agreeableness $(\alpha=0,79)$, Conscientiousness $(\alpha=0,7 \mathrm{I})$, and Openness $(\alpha=0,75)$.

\section{Data collection}

Data gathering was conducted on an online survey. The links of the online survey were distributed to various WhatsApp groups and other social media. The target of the people who filled out the survey were people who have been volunteered. The data of the personality of non-volunteer participants were obtained from the data of the Akhtar's (2018) study. Participants who did not have activities outside of their work or lectures are designated as non-volunteers. The participants were given short information related to the goal of the research. The participants completed the questionnaire about the demographic data and the Ten Item Personality Inventory (TIPI) only if they were willing to participate in the research.

\section{Data analysis}

Data analysis was conducted in two steps. First, I performed a preliminary analysis using independent sample t-test to determine the difference of each of personality traits between volunteer and non-volunteer samples. Second, I conducted a binary logistic regression analysis. Binary logistic regression was conducted to find out what kind of specific personality characteristics were dominant to increase the tendency to become volunteers. The analysis of the first and the second step was conducted using SPSS 23. 


\section{Result}

Preliminary analysis

Preliminary analysis was conducted using independent sample t-test analysis to compare each of big five personality traits between volunteer and non-volunteer. Analysis of independent sample t-test showed that there was statistically significant difference of all the big five personality traits between volunteer and non-volunteer. Volunteer $(M=9,63 ; S D=$ $2,44)$ reported significantly higher levels of extraversion than non-volunteer $(M=8,37 ; S D=$ $2,91), \mathrm{t}(4 \mid 8)=4,83 ; \mathrm{p}<0,01$. Volunteer $(M=10,78 ; S D=1,7)$ reported significantly higher levels of agreeableness than non-volunteer $(M=10,4 I ; S D=1,96), t(4 I 8)=2,04 ; p<0,05$. Volunteer $(M=10,88 ; S D=1,89)$ reported significantly higher levels of conscientiousness than non-volunteer $(M=9,47 ; S D=2,08), t(4 I 8)=7,28 ; p<0,01$. Volunteer $(M=9,99 ; S D=$ $2,3 \mathrm{I})$ reported significantly higher levels of emotional stability than non-volunteer $(M=9,16$; $S D=2,48), t(4 I 8)=3,56 ; p<0,0 I$. Volunteer $(M=11,26 ; S D=1,97)$ reported significantly higher levels of openness than non-volunteer $(M=10,36 ; S D=1,95), t(4 I 8)=4,68 ; p<0,01$. Thus, it can be infered that volunteer samples reported significantly have higher levels of agreeableness, conscientiousness, extraversion, emotional stability, and openness than nonvolunteer samples. Personality distinctions between volunteer and non-volunteer is showed at table I.

Table I

Personality distinctions between volunteer and non-volunteer

\begin{tabular}{lccccc}
\hline \multirow{2}{*}{ Traits } & \multicolumn{2}{c}{ Volunteer $(\mathrm{N}=215)$} & \multicolumn{2}{c}{$\begin{array}{c}\text { Non-volunteer } \\
(\mathrm{N}=205)\end{array}$} & \multirow{2}{*}{$\mathrm{t}$} \\
\cline { 2 - 5 } & $\mathrm{M}$ & $\mathrm{SD}$ & $\mathrm{M}$ & $\mathrm{SD}$ & \\
\hline Extraversion & 9,63 & 2,44 & 8,37 & 2,91 & $4,83^{* *}$ \\
Agreeableness & 10,78 & $\mathrm{I}, 7$ & 10,41 & 1,96 & $2,04^{*}$ \\
Conscientiousness & 10,88 & 1,89 & 9,47 & 2,08 & $7,28^{* *}$ \\
Emotional Stability & 9,99 & 2,31 & 9,16 & 2,48 & $3,56 * *$ \\
Openness & 11,26 & 1,97 & 10,36 & 1,95 & $4,68^{* *}$ \\
\hline
\end{tabular}

* Significant at the 0,05 level (2-tailed)

** Significant at the 0,0 I level (2-tailed) 
Logistic Regression

The Omnibus Tests of Model Coefficients is conducted to examine that the new model, including the big five personality traits, is an enhancement over the baseline model. The chisquare is highly significant $\left(\chi^{2}=67,102 ; d f=5 ; p<, 0 I\right)$ so the new model is significantly better. The model explained 19,7\% (Nagelkerke $R^{2}$ ) of the variance in volunteer participation. The Hosmer \& Lemeshow test of the goodness of fit indicates that the model is a good fit to the data as $p=0,209(>0,05)$. The observed and predicted classifications of volunteer are reported in table 2 .

Table 2

The predicted and the observed frequencies for participation in volunteering by logistic regression

\begin{tabular}{lcccc}
\hline \multirow{2}{*}{ Observed } & \multicolumn{3}{c}{ Predicted } \\
\cline { 3 - 4 } & \multicolumn{3}{c}{ Status } & Percentage \\
& & non-volunteer & volunteer & Correct \\
\hline \multirow{2}{*}{ Status } & Non-volunteer & 127 & 78 & 62,0 \\
& Volunteer & 73 & 142 & 66,0 \\
\hline Overall Percentage & & 64,0 \\
\hline Note: & & & \\
- The cut value is 0,5 & & & \\
- Sensitivity=62\%, Specificity $=66 \%$ & & &
\end{tabular}

As shown in Table 2, 127 participants were correctly predicted to be a non-volunteer by the model, and 142 were correctly predicted to be a volunteer. This result was also supported by the size of specificity (66\%) compared to the size of sensitivity (62\%). Sensitivity measures the extent of accurately classified occurrences (i.e., those are a volunteer), whereas specificity measures the extent of accurately classified non-occurrences (those are not volunteer). In general, the correct overall prediction was $64 \%$.

Table 3 shows the contribution of each independent variable to the model and its statistical significance. From these results it can be inferred that Extraversion (Wald=8,48; $d f=I$; $\mathrm{P}<0,0 \mathrm{I}$ ) and conscientiousness (Wald=2I,48; $d f=I ; p<0,0 \mathrm{I}$ ) added significantly to the prediction of volunteering, but agreeable (Wald=0,2l; $d f=I ; p>0,05)$, emotional stability $(W a l d=I, 6 I ; \quad d f=I ; p>0,05)$, and openness (Wald=2,92; $d f=I ; p>0,05)$ did not add 
significantly to the prediction. Increasing extraversion and conscientiousness was significantly associated with an increased likelihood of volunteer participation. Thus, extraversion and conscientiousness were the best predictors of participation in volunteering.

Table 3

Logistic regressions analysis with participation in volunteering as a dependent variable and big five personality traits as independent variables

\begin{tabular}{lcccccc}
\hline \multicolumn{1}{c}{ Predictors } & B & df & S.E. & Wald & Sig. & Exp(B) \\
\hline Extraversion & 0,121 & I & 0,041 & 8,485 & 0,004 & I, I28 \\
Agreeableness & $-0,03$ & I & 0,064 & 0,218 & 0,641 & 0,971 \\
Conscientiousness & 0,287 & I & 0,062 & 21,485 & 0,001 & 1,333 \\
Emotional Stability & 0,064 & $\mathrm{I}$ & 0,05 & $\mathrm{I}, 6 \mathrm{II}$ & 0,204 & $\mathrm{I}, 066$ \\
Openness & $0,10 \mathrm{I}$ & & 0,059 & 2,922 & 0,087 & $\mathrm{I}, 106$ \\
Constant & $-5,359$ & & 0,919 & 34,032 & 0,001 & 0,005 \\
\hline
\end{tabular}

\section{Discussion}

This research aims to determine differences in personality characteristics between volunteers and non-volunteers. This research also intends to predict participation in volunteering based on their personality characteristics. This study involved 215 volunteers from various sectors. The preliminary analysis findings indicate that distinctions exist between non-volunteers and volunteers in terms of their personality. The volunteer reported significantly have higher levels of emotional stability, extraversion, agreeableness, conscientiousness, and openness. This finding supports previous studies about the differences personality characteristics between volunteer and non-volunteer (Herzog \& Morgan, 1993; Spitz \& MacKinnon, 1993; Omoto, Snyder and Hackett, 20I0; Carlo et al., 2005; Gu et al., 2013).

Extraversion is connected with assertiveness, sociability, and positive emotions (McCrae, 2009). Because volunteerism often requires extensive social interaction, it is reasonable if the result of this study connects extraversion with volunteering. Agreeableness is also the core characteristics of volunteering (Graziano \& Eisenberg, 1997). Agreeable individuals are 
associated with altruistic, trusting, soft-hearted, modest, and compliant. They tend to be prosocial and increase the likelihood of volunteer participation. This result also supports findings from Carlo et al. (2005), which indicate that extraversion and agreeableness are the two main characters that volunteers have.

This finding also indicates that volunteers significantly have a higher level of conscientiousness, emotional stability, and openness. Conscientiousness includes the characteristics of order, efficient, self-organized, and, logic. Emotional stability is the opposite of neuroticism that expresses anxiety, tension, excision, depression, and hostility. Finally, openness contains curiosity, artistry, flexibility, and wisdom. Volunteering is an activity outside the individual's main activities to work or study. Therefore, it is necessary to organize the main activities and volunteer activities to run well. Also, volunteering means getting out of the comfort zone. Therefore people who are anxious to face the new environment will find it difficult to participate in volunteering. Conversely, people who have high curiosity will tend to participate in volunteering. Thus, it is reasonable if people who have a high level of conscientiousness, emotional stability, and openness have a higher possibility to participate in volunteering.

This study also wanted to find out what personality characteristics were able to predict participation in volunteering using analysis of logistic regression. The logistic regression model was statistically significant, $\chi^{2}=67,102, P<, 01$. The model explained $19,7 \%$ (Nagelkerke $\mathrm{R}^{2}$ ) of the variance in volunteer participation and correctly classified $64 \%$ of cases. The logistic regression also showed that Extraversion and Conscientiousness are two major predictors of participation in volunteering.

The fact that extraversion and conscientiousness are two predictors of participation in volunteering is reasonable. Mostly the volunteers are employees in corporate and college students. So that people whose conscientiousness level is high tend to be able to manage their time to carry out their obligations and participate in voluntary activities. In addition, extraverted people are identified with those who like to hang out with many people and take on the role of being a leader (McCrae, 2009). Thus they tend to expand their social relations by participating in voluntary activities. 
However, the unique finding of this study is that agreeableness was not significant in predicting participation as volunteers. Many researchers (Graziano \& Eisenberg, 1997; Carlo et al., 2005) emphasize that agreeableness is the main character that can predict participation as volunteers. According to the descriptive data of this study, it is noted that the level of agreeableness in both volunteer and non-volunteer samples is high, and this is typical of Indonesian people. That fact causes the character of agreeableness is not a unique variable that can distinguish volunteers and non-volunteers, especially in Indonesian people.

Finally, this study has completed previous studies that investigated the differences in personality characteristics. This study provides reference for relevant organizations to recruit and manage their volunteers. Volunteers tend to have openness, extraversion, agreeableness, conscientiousness, and emotional stability that are higher than nonvolunteers. This information implies volunteer recruitment. The organizations need to frame their recruitment messages to attract applicants with certain personality characteristics. For example, to attract volunteer who is extraverted, the recruitment messages of the organization must emphasize the benefits of being volunteers such as expanding their networking and the opportunity to lead.

This research still has some limitations in terms of the instrument used in the study as well as the sample. This study used the Ten Item Personality Inventory (TIPI) to examine the personality of the participants. Akhtar (2018) stated that TIPI Indonesia is only appropriate when the time is limited, and comprehensive assessments of personality are not required. TIPI is only capable of measuring the main factors of personality but is not capable of measuring a more narrow facet. It is advisable to use another instrument, such as NEO-PI-R to asses a comprehensive personality diagnosis of participants. This study also used a crosssectional study to predict participation in volunteering. However, a cross-sectional study has some limitations, specifically in the determination of cause and effect. This study also cannot be used to analyze behavior over a period to time. Regarding the sample, volunteer groups were dominated by volunteers from the education sector, so this sample could not properly represent all volunteers in Indonesia. 


\section{Conclusion}

This research is in line with early assumptions that there are differences in personality characteristics between volunteer and non-volunteer. Volunteers tend to have higher openness, extraversion, conscientiousness, emotional stability, and agreeableness than nonvolunteers. Extraversion and Conscientiousness are the two main predictors of participation in volunteering. The unique finding of this study is that agreeableness was not significant in predicting participation as volunteers in Indonesia samples. It is noted that certain personality characteristics can predict participation in volunteering. Related to this finding, non-profit organizations need to frame their recruitment messages to attract applicants with certain personality characteristics. The future researchers are also suggested to assess more narrow facet of personality using another measure of personality and involving various samples of the volunteer.

\section{Acknowledgment}

The author wishes to express the gratitude to the Faculty of Psychology, University of Muhammadiyah Malang who facilitated the writing of this research

\section{References}

Akhtar, H. (20I8). Translation and validation of the Ten-Item Personality Inventory (TIPI) into Bahasa Indonesia. International Journal of Research Studies in Psychology, 7(2). https://doi.org// 0.586 I/ijrsp.2018.3009

Akhtar, H. (2017). Psychological well-being of volunteer teacher trainers in the remote area in Indonesia. International E-Journal of Advances in Social Sciences. 3(9), 840-849. https://dx.doi.org//0.18769/ijasos.366855

Carlo, G., Okun, M. A., Knight, G. P., \& de Guzman, M. R. T. (2005). The interplay of traits and motives on volunteering: agreeableness, extraversion, and prosocial value motivation. Personality and Individual Differences, 38(6), I293-1305. https://doi.org/I0.1016/j.paid.2004.08.012 
Clary, E. G., Snyder, M., \& Ridge, R. (1992). Volunteers' motivations: A functional strategy for the recruitment, placement, and retention of volunteers. Nonprofit Management and Leadership, 2(4), 333-350.

Clary, E. G., Snyder, M., Ridge, R. D., Copeland, J., Stukas, A. A., Haugen, J., \& Miene, P. (1998). Understanding and assessing the motivations of volunteers: a functional approach. Journal of Personality and Social Psychology, 74(6), 1516.

Gastañaduy, K., Paredes, D. H., \& Lens, W. (20I4). Work motivation and psychological wellbeing of volunteers and non-volunteers. Revista de Orientacion Educacional, (53), 37-50.

Gosling, S. D., Rentfrow, P. J., \& Swann, W. B. (2003). A very brief measure of the Big-Five personality domains. Journal of Research in Personality, 37(6), 504-528. https://doi.org/I0.1016/S0092-6566(03)00046-I

Graziano, W. G., \& Eisenberg, N. H. (1997). Agreeableness: a dimension of personality. In R. Hogan, J. Johnston, \& S. Briggs (Eds.), Handbook of personality psychology (pp. 795-824). San Diego, CA: Academic Press.

Gu, Y., Gu, D., Wei, Q., Pan, S., Chen, W., \& Ge, Y. (20/3). An Empirical Study on Personality Characteristics of College Volunteers: Based on the Collected Data from Shanghai Expo. Procedia - Social and Behavioral Sciences, 83, 969-974. https://doi.org/10.1016/j.sbspro.2013.06.180

Herzog, A. R., \& Morgan, J. N. (1993). Formal volunteer work among older Americans. In S. A. Bass, F. G. Caro, \& Y. Chen (Eds.), Achieving a productive aging society (pp. I| 9-|42). Connecticut: Greenwood Publishing.

Juzbasic, M., \& Vukasovic Hlupic, T. (2015). Personality Traits and Motives for Volunteering. Psychological Topics, 24(2), 279-304-304.

McCann, S. J. H. (20I7). Higher USA State Resident Neuroticism Is Associated With Lower State Volunteering Rates. Personality and Social Psychology Bulletin, 43(I2), 1659-1674. https://doi.org/I0.1 I77/0I46/67217724802

McCrae, R. R. (2009). Personality profiles of cultures: Patterns of ethos. European Journal of Personality, 23(3), 205-227. https://doi.org/I0.1002/per.7I2

Omoto, A. M., \& Snyder, M. (1995). Sustained helping without obligation: motivation, the longevity of service, and perceived attitude change among AIDS volunteers. Journal of Personality and Social Psychology, 68, 67I-686.

Omoto, A. M., Snyder, M., \& Hackett, J. D. (2010). Personality and motivational antecedents of activism and civic engagement. Journal of Personality, 78(6), 1703-1734. doi: I0.1 III/j.|467-6494.20I0.00667.x

Pushkar, D., Reis, M., \& Morros, M. (2002). Motivation, personality, and well-being in older volunteers. The International Journal of Aging and Human Development, 55(2), I4I-162. 
Savitri, N.G. (2005). Panduan Manajemen Kerelawanan. Depok: Piramedia

Skoglund, A.G. (2006). Do not forget about your volunteers: a qualitative analysis of factors influencing volunteer turnover. Health \& social work.3 I(3):2I 7-20

Snyder, M., \& Omoto, A. M. (2008). Volunteerism: Social issues perspectives and social policy implications. Social Issues and Policy Review, 2(I), I-36. https://doi.org/I0.I I I I/j. I 75I-2409.2008.00009.x

Spitz, R., \& MacKinnon, J. (1993). Predicting success in volunteer community service. Psychological Reports, 73, 815-818.

Tabassum, F., Mohan, J., \& Smith, P. (2016). Association of volunteering with mental wellbeing: a life-course analysis of a national population-based longitudinal study in the UK. BMJ Open, 6(8), e0I I 327.

Whillans, A. V., Seider, S. C., Chen, L., Dwyer, R. J., Novick, S., Gramigna, K. J., ... Dunn, E. W. (2016). Does volunteering improve well-being? Comprehensive Results in Social Psychology, I (I-3), 35-50.

Wilson, J. (2000). Volunteering. Annual Review of Sociology, 26, 21 5-240

Windsor, T. D., Anstey, K. J., \& Rodgers, B. (2008). Volunteering and psychological wellbeing among young-old adults: How much is too much? The Gerontologist, 48(I), 59-70. 